\title{
Interactive classification and spatial modeling of land cover changes in the Slovak Republic in the period 1990 to 2018
}

\author{
Filip Moravcik ${ }^{\text {a }}$ Eva Micietova ${ }^{\text {a }}$ \\ ${ }^{a}$ Comenius University in Bratislava, Faculty of Natural Sciences, Filip Moravcik-moravcik48@uniba.sk, Eva Micietova- \\ eva.micietova@uniba.sk
}

Keywords: land cover, AFOLU, Bratislava region, web application, spatial modeling

\begin{abstract}
:
The current country is the result of changes from the original country, mainly due to human influence. The external appearance of the landscape is represented by landscape cover. Within the EU, the Copernicus program, coordinated by the European Environment Agency (EEA), is dedicated to Earth and environmental monitoring. The outputs of the program are information services based on satellite observations of the Earth and ground-based collection of spatial data - implemented in cooperation with individual Member States of the EU. The Copernicus Land Monitoring Service (CLMS) and the collection of geographical information about land cover and land cover changes, land use, vegetation status, water cycles and the energy of the Earth's surface are provided.
\end{abstract}

The Slovak Republic has been involved in the program since 1990. Corine Land Cover (CLC) data are freely available for 1990, 2000, 2006, 2012 and 2018. The CLC legend is a mutual combination of land cover and land use, the highest third hierarchical level of the CLC classification identifies 44 classes. Data are available in the form of vectors and rasters, with a scale of $1: 100000$, coordinate system: ETRS89, minimum mapping unit of 25 ha was selected.

In this paper, we focus on the identification of the condition and spatial modeling of landscape changes with emphasis on forests. Forests as important carbon sinks are an environmental factor that influences the impact of emissions on the development of greenhouse gases and climate change. According to the Intergovernmental Panel on Climate Change (IPCC), member countries report changes in land cover categories according to the AFOLU (Agriculture, Forestry and Other Land Use) classification. For the purposes of estimating greenhouse gas emissions, the AFOLU methodology distinguishes six categories: forest land; cropland; grassland; wetlands; settlements; other areas.

The main goal of the paper is the development and presentation of an integrated geographical database of land cover data of the Slovak Republic from CLC datasets (in the period 1990 to 2018), a tool for reclassification of the third hierarchical level CLC and creation of data structures of land use categories according to AFOLU.

The specific goal is the development and presentation of an interactive tool - a web application for retrospective assessment of land cover changes from the integrated geographical database according to the CLC classification and interactive assessment of land cover changes according to the AFOLU classification. The outputs of the interactive evaluation of land cover changes will focus on the forest land cover category, evaluation of changes according to adjustable time intervals in CLC and AFOLU and the statistical evaluation of changes.

The output is a freely available web application with interactive functionality for datasets, database modeling of land cover changes, statistical evaluation of changes and creation of map outputs. A case study of data processing for the area of the Bratislava region (205 270 ha) in the years 1990 to 2018 (five CLC datasets) is presented. The datasets are suitable for continuously identifying the state of land cover, modeling its changes over time and interpreting land cover change processes over time.

\section{Acknowledgements}

The paper was elaborated within the project No. UK/144/2020 „Impact of changes in the spatial structure of land cover on global environmental risks“" provided by Comenius University in Bratislava. 